\title{
A DISCRETE MODEL FOR THE DESIGN SENSITIVITY ANALYSIS OF MULTI-LAYERED COMPOSITE SHELLS OF REVOLUTION
}

\author{
Cristovão M. Mota Soares, N. M. Marques Cordeiro \\ IDMEC-Instituto de Engenharia Mecânica, IST, Av. Rovisco Pais, 1096 Lisboa Codex, Portugal \\ and \\ J. Infante Barbosa \\ ENIDH-Departamento de Máquinas Marítimas, Paço de Arcos, 2780 Oeiras, Portugal
}

(Received 5 May 1994; final version accepted 28 January 1995)

\begin{abstract}
This paper studies the sensitivity analysis for the optimization of the multi-layered composite axisymmetric shells subjected to arbitrary static loading and free vibrations. The structural analysis is carried out using a two node frustum-cone finite element with 16 degrees of freedom based on Love-Kirchhoff assumptions. The design variables are the angle of orientation of the fibers and/or the vectorial distances from middle surface to upper surface of each ply. The constraint functions are displacements, stresses (Tsai-Hill criterion) and the natural frequency of a specified mode shape. Four types of objective functions can be used: maximum displacement or natural frequency or elastic strain energy and material volume. The design sensitivities are calculated analytically, semi-analytically and by global finite difference. The potentiality of the proposed model and the accuracy of the sensitivities of response are discussed with reference to the applications
\end{abstract}

\section{INTRODUCTION}

The use of composite materials is having a great impact in the design process of structural components encountered in engineering practice with great relevance in pressure vessel, aerospace, automobile, naval and defense industries. These materials allow the designer to tailor make the structure or component and therefore structural optimization techniques are of great importance in the pre-design and design of these materials and structures to improve the stiffness, reduce the weight, increase payload or to improve the performance in general. For a successful optimization the requirements are a good finite element model, adequate sensitivities, proper choice of objective functions, design variables and constraints and a suitable method of solution of the non-linear mathematical problem. The evaluation of sensitivities of structural response to changes in design variables is a crucial stage in the optimal design representing a major factor with respect to computing time required for the optimization process. Hence it is important to have efficient techniques to calculate these derivatives.

In this work a discrete model for the optimal structural design of thin composite laminated axisymmetric shell structures subject to symmetric and/or asymmetric loading is presented. The structural analysis is carried out using a frustum-cone finite element with 16 degrees of freedom based on Love-Kirchhoff assumptions (Kraus, 1967). For thin axisymmetric shell structures, which takes into consideration the coupling effect between the symmetric and antisymmetric displacements of these anisotropic multilayered light structures as described in Sheinman and Weissman (1987).

The sensitivities with respect to the design variables, namely angle of orientation of the fibers and/or the vectorial distances from middle surface to upper surface of each ply (indirectly the plies thicknesses) are evaluated analytically and alternatively semianalytically or by global finite difference. The simplest technique of evaluating sensitivities of response to changes in design variables is through the finite difference approximation, called global finite difference, which is computationally expensive.

The use of a discrete model using analytical sensitivities (Haftka and Gurdal, 1993) or alternatively with semi-analytical techniques as in Zienkiewicz and Campbell (1973) and 
Barthelemy et al. (1988) is very promising when the source code is available. The sensitivity analysis algorithms are easily implemented inside the source code by its modification.

In the present work the discrete model approach will be extended to carry out the sensitivity analysis and optimization of thin axisymmetric shells made of symmetric or asymmetric multi-layered composite lay-ups using the adjoint structure technique (Haftka and Kamat, 1987) for static type situations.

Other numerically based solutions for isotropic axisymmetric structures were presented by Marcelin and Trompette (1988) using a similar two node straight element and/or a three node parabolic element based in Love-Kirchhoff shell theory associated to the semi-analytical method to evaluate shape sensitivities. Barbosa et al. (1991) and Mota Soares et al. (1994) developed a similar discrete model, for isotropic axisymmetric shells, where shape sensitivities were evaluated analytically using a symbolic manipulator. Other authors, Plaut et al. (1984) and Chenais (1987), presented alternative theories and models for the optimization of isotropic shell structures. Mehrez and Rousselet (1989), studied the analysis and optimization of shells of revolution using Koiter's model with the implementation of B-splines for the middle surface and finite element for displacements. Also, Bernadou et al. (1991), using a general continuous formulation of the problems, presented a methodology for optimizing the shape (middle surface and thickness) of an elastic isotropic general thin shell under different criteria.

Very recently the optimal design of composite lightweight cylindrical rollers was carried out by Bellendir and Eschenauer (1993) using closed form solutions for the structural analysis based upon the cylindrical shell equations according to Flügge in the scope of the classical laminate theory. Also Zimmermann (1993) studied structural optimization of thin walled fiber composite cylindrical structures which are endangered by buckling and influenced by geometrical imperfections. All previous research, in design sensitivity analysis of axisymmetric shells subjected to arbitrary loading, was mainly concerned with isotropic or unilayered orthotropic thin structures or in very specific shell applications such as cylinders and in pressure vessel components as in Muc (1992) and Blachut (1993) among many others.

The increased use of these light axisymmetric structures made of multilayered composite materials, the importance of the coupling effect between symmetric and antisymmetric displacement components, which have been included in the structural analysis by Sheinman and Weissman (1987), and the lack of sensitivity studies for these structures are the motivations for the present work.

A comparative study of analytical versus semi-analyical and global finite difference shows that, with regard to the accuracy, all techniques give similar sensitivity results for the two types of design variables which were considered.

The formulation presented in this paper can be applied to the minimization of maximum displacement or the minimization of the strain energy or the maximization of the natural frequency of a chosen vibration mode of thin multi-laminated composite axisymmetric shell structures. The minimization of the volume of the shell material subjected to constraints on displacements, stresses (Tsai-Hill criterion) and natural frequencies can also be accomplished.

The ADS (Automated Design Synthesis) program of Vanderplaats (1987) is used to solve the nonlinear mathematical programming problem.

\section{LAMINATE ANALYSIS}

The constitutive relations, considering a thin ply $k$ of fibers plus matrix, where the principal orthogonal material axes are $\left(x_{1}, x_{2}, \xi\right)$, and axis $x_{1}$ is parallel to the fibers (Fig. 1), can be represented for a plane stress situation as in Vinson and Sienakowski (1986):

$$
\begin{gathered}
\sigma_{k}^{*}=Q_{k} \varepsilon^{*} \\
\sigma_{k}^{*}=\left[\begin{array}{lllll}
\sigma_{11} & \sigma_{22} & \sigma_{12}
\end{array}\right]^{T} ; \quad \underline{\varepsilon}^{*}=\left[\begin{array}{llll}
\varepsilon_{11} & \varepsilon_{22} & \gamma_{12}
\end{array}\right]^{T}
\end{gathered}
$$

where the components of normal and shearing stresses are, respectively, $\sigma_{11}, \sigma_{22}$ and $\sigma_{12}$ and the components of normal and shear strains are $\varepsilon_{11}, \varepsilon_{22}$ and $\gamma_{12}$, respectively. 


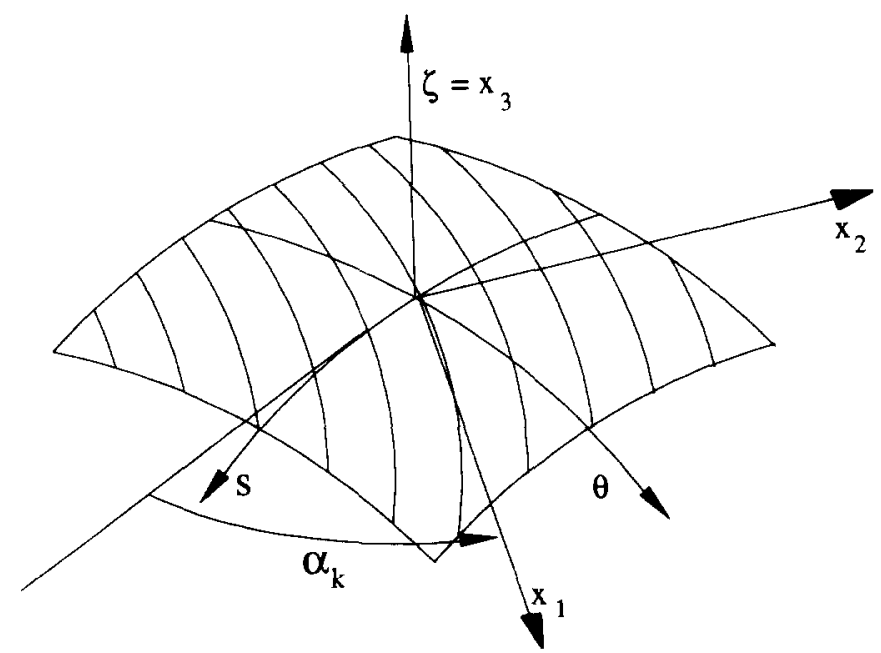

Fig. 1. Shell convention for orthotropic construction. Fiber orientation angle $\alpha_{k}$.

The nonzero material coefficient $\left(Q_{i j}\right)_{k}(i, j=1,2,6)$ for the $k$ th ply are:

$$
\begin{aligned}
& Q_{11}=E_{1} /\left(1-v_{12} v_{21}\right) \\
& Q_{22}=E_{2} /\left(1-v_{12} v_{21}\right) \\
& Q_{12}=Q_{21}=E_{2} v_{12} /\left(1-v_{12} v_{21}\right) \\
& Q_{66}=G_{12}
\end{aligned}
$$

where $E_{1}, E_{2}, G_{12}$ nd $v_{12}$ are the independent material properties in terms of engineering constants for orthotropic ply $k$. Relating eqn (1) with orthotropic properties in the shell coordinate axes $(S, \theta, \xi)$, the constitutive relations become:

$$
\begin{aligned}
\underline{\sigma}_{k} & =\bar{Q}_{k} \varepsilon \\
\sigma_{k} & =\left[\begin{array}{lll}
\sigma_{S S} & \sigma_{\theta \theta} & \sigma_{S \theta}
\end{array}\right]^{T} \\
\underline{\varepsilon} & =\left[\begin{array}{lll}
\varepsilon_{S S} & \varepsilon_{\theta \theta} & \gamma_{S \theta}
\end{array}\right]^{T}
\end{aligned}
$$

where $\sigma_{S S}, \sigma_{\theta \theta}, \sigma_{s \theta}$ are the meridional, circumferential and shear stress components, $\varepsilon_{S S}, \varepsilon_{\theta \theta}, \gamma_{S \theta}$ the corresponding strain components.

The coefficients of $\bar{Q}_{k}$ can be represented in an efficient and useful way (Tsai and Hahn, 1980) as:

$$
\begin{aligned}
& \bar{Q}_{11}=U_{1}+U_{2} \cos \left(2 \alpha_{k}\right)+U_{3} \cos \left(4 \alpha_{k}\right) \\
& \bar{Q}_{12}=\bar{Q}_{21}=U_{4}-U_{3} \cos \left(4 \alpha_{k}\right) \\
& \bar{Q}_{22}=U_{1}-U_{2} \cos \left(2 \alpha_{k}\right)+U_{3} \cos \left(4 \alpha_{k}\right) \\
& \bar{Q}_{16}=\bar{Q}_{61}=\frac{1}{2} U_{2} \sin \left(\alpha_{k}\right)+U_{3} \sin \left(4 \alpha_{k}\right) \\
& \bar{Q}_{26}=\bar{Q}_{62}=\frac{1}{2} U_{2} \sin \left(\alpha_{k}\right)-U_{3} \sin \left(4 \alpha_{k}\right) \\
& \bar{Q}_{66}=U_{5}-U_{3} \cos \left(4 \alpha_{k}\right)
\end{aligned}
$$

where the invariant $U_{i}$ are:

$$
\begin{aligned}
& U_{1}=\frac{1}{8}\left(3 Q_{11}+3 Q_{22}+2 Q_{12}+4 Q_{66}\right) \\
& U_{2}=\frac{1}{2}\left(Q_{11}-Q_{22}\right) \\
& U_{3}=\frac{1}{8}\left(Q_{11}+Q_{22}-2 Q_{12}-4 Q_{66}\right) \\
& U_{4}=\frac{1}{8}\left(Q_{11}+Q_{22}+6 Q_{12}-4 Q_{66}\right) \\
& U_{5}=\frac{1}{8}\left(Q_{11}+Q_{22}-2 Q_{12}+4 Q_{66}\right)
\end{aligned}
$$

and $\alpha_{k}$ is the fiber orientation angle of the $k$ th ply (Fig. 1). 


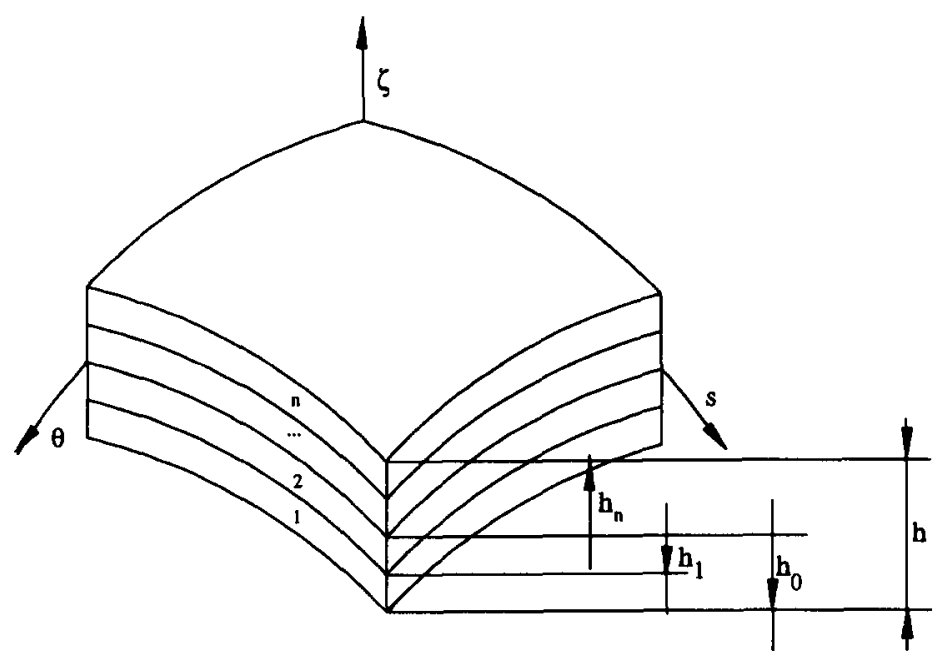

Fig. 2. Laminate nomenclature.

The strain vector $\varepsilon$ at an arbitrary point of the $k$ th ply is given for the Love-Kirchhoff model as in Kraus (1967):

$$
\begin{aligned}
\underline{\varepsilon} & =\underline{\varepsilon}^{0}+\xi \underline{\chi} \\
\underline{\varepsilon}^{0} & =\left[\begin{array}{lll}
\varepsilon_{S S}^{0} & \varepsilon_{\theta \theta}^{0} & \gamma_{S \theta}^{0}
\end{array}\right]^{T} \\
\underline{\sim} & =\left[\begin{array}{lll}
\chi_{S S} & \chi_{\theta \theta} & \chi_{s \theta}
\end{array}\right]^{T}
\end{aligned}
$$

where $\varepsilon^{0}$ and $\chi$ are the vectors of strain components for membrane and bending effects in shell referential axes $(S, \theta, \xi)$. Substituting eqn (21) into the constitutive relation eqn (7), the stresses for the $k$ th layer are computed as:

$$
\sigma_{k}=\bar{Q}_{k}\left(\varepsilon^{0}+\xi \underline{\chi}\right) \text {. }
$$

The internal membrane forces $\bar{\sim}=\left[\begin{array}{lll}N_{s s} & N_{\theta \theta} & N_{s \theta}\end{array}\right]^{T}$ and the bending moments $\bar{M}=\left[\begin{array}{lll}M_{S S} & M_{\theta \theta} & M_{S \theta}\end{array}\right]^{T}$ are obtained by integrating layer by layer through the cross section giving:

$$
\begin{aligned}
& {\left[\begin{array}{c}
\bar{N} \\
\overline{\bar{M}}
\end{array}\right]=\left[\begin{array}{ll}
A & B \\
B & D
\end{array}\right]\left[\begin{array}{c}
\underbrace{0} \\
\underset{\sim}{\chi}
\end{array}\right]} \\
& A_{i j}=\sum_{k=1}^{N L}\left(\bar{Q}_{i j}\right)_{k}\left(h_{k}-h_{k-1}\right) \\
& B_{i j}=\frac{1}{2} \sum_{k=1}^{N L}\left(\bar{Q}_{i j}\right)_{k}\left(h_{k}^{2}-h_{k-1}^{2}\right) \\
& D_{i j}=\frac{1}{3} \sum_{k=1}^{N L}\left(\bar{Q}_{i j}\right)_{k}\left(h_{k}^{3}-h_{k-1}^{3}\right)
\end{aligned}
$$

where $h_{k}$ is the vectorial distance from the laminate middle surface to the upper surface of the $k$ th ply as represented in Fig. 2 and $N L$ represents the total number of plies. The cross-sectional rigidity constants of the laminate for membrane, membrane/bending coupling and bending are $A_{i j}, B_{i j}$ and $D_{i j}$, respectively.

\section{SENSITIVITY ANALYSIS OF AXISYMMETRIC SHELLS}

\section{Analytical method}

For the present frustum-conical element (Fig. 3) the strain components for membrane and bending effects are given, as in Zienkiewicz (1977) and Kraus (1967), by:

$$
\begin{aligned}
\varepsilon^{\circ} & =\Delta_{\mathrm{m}} \underline{\underline{u}} \\
\underline{\sim} & =\Delta_{\mathrm{f}} \underline{\mathbf{u}}
\end{aligned}
$$




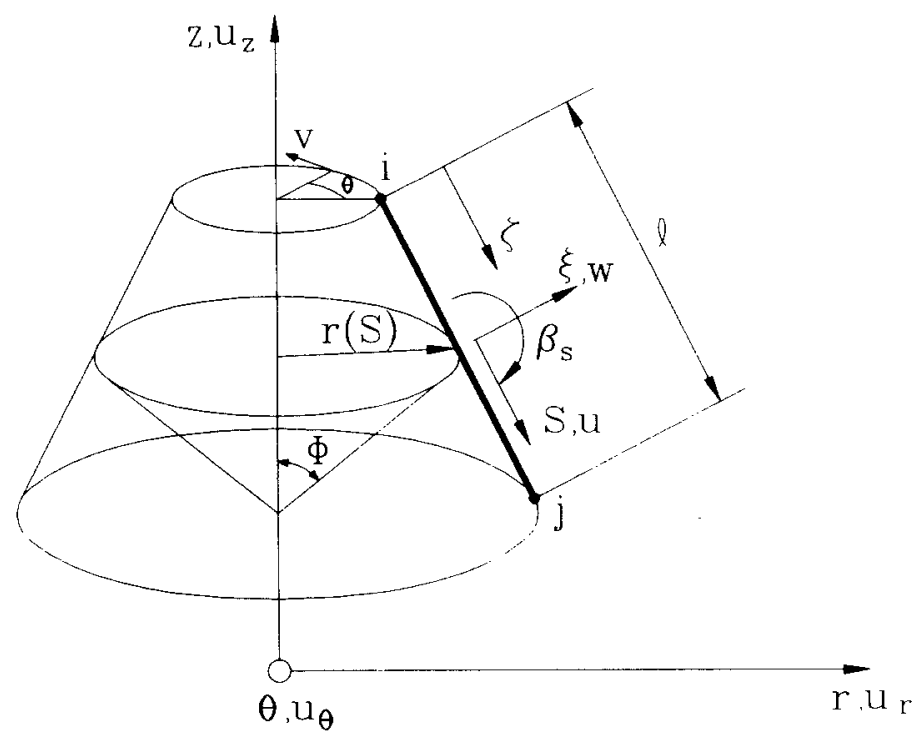

Fig. 3. Frustum-cone finite element. Geometry and displacements.

where the operators $\Delta_{\mathrm{m}}$ and $\Delta_{\mathrm{f}}$ are:

$$
\begin{gathered}
\Delta_{\mathrm{m}}=\left[\begin{array}{ccc}
\frac{\partial}{\partial S} & 0 & 0 \\
\frac{\cos \phi}{r} & \frac{\sin \phi}{r} & \frac{1}{r} \frac{\partial}{\partial \theta} \\
\frac{1}{r} \frac{\partial}{\partial \theta} & 0 & \left(\frac{\partial}{\partial S}-\frac{\cos \phi}{r}\right)
\end{array}\right] \\
\Delta_{\mathrm{f}}=\left[\begin{array}{ccc}
0 & -\frac{\partial^{2}}{r^{2}}\left(\frac{\partial^{2}}{\partial \theta^{2}}+r \cos \phi \frac{\partial}{\partial S}\right) & \frac{\sin \phi}{r^{2}} \frac{\partial}{\partial \theta} \\
0 & \frac{2}{r^{2}}\left(\cos \phi \frac{\partial}{\partial \theta}-r \frac{\partial^{2}}{\partial S \partial \theta}\right) & \frac{2 \sin \phi}{r^{2}}\left(r \frac{\partial}{\partial S}-\cos \phi\right)
\end{array}\right]
\end{gathered}
$$

and $\phi$ is the angle between the normal and the shell surface and $r$ is the radial coordinate. The displacement vector $\underline{\mathbf{u}}=[u, w, v]^{T}$, with components $u, w$ and $v$ in the tangential, normal and circumferential directions, in the element coordinate axes $(S, \theta, \xi)$ respectively, are expanded in Fourier series of the type:

$$
\begin{gathered}
\underline{\mathbf{u}}=\sum_{n=0}^{N} \mathbf{C}_{n} \underline{\mathbf{u}}_{n} \\
\mathbf{C}_{n}=\left[\begin{array}{cccccc}
\cos n \theta & 0 & 0 & \sin n \theta & 0 & 0 \\
0 & \cos n \theta & 0 & 0 & \sin n \theta & 0 \\
0 & 0 & \sin n \theta & 0 & 0 & \cos n \theta
\end{array}\right]
\end{gathered}
$$

where $n$ is the Fourier index and $N$ is the number of terms in the truncated Fourier series and $\underline{\mathbf{u}}_{n}=\left[\begin{array}{ll}\underline{\mathbf{u}}_{n}^{1} & \underline{\mathbf{u}}_{n}^{2}\end{array}\right]^{T}$ is the vector of displacement components amplitudes, designating superscript 1 and 2 the symmetric and antisymmetric displacement amplitudes. 
The meridional dependence of the displacements amplitudes can be written in a product form as:

$$
\begin{aligned}
& \underline{\sim}_{n}=\mathfrak{N} \underline{\underline{q}}_{n}^{\text {fe }} \\
& \underline{\mathbf{q}}_{n}^{l \mathrm{e}}=\mathbf{L} \mathbf{q}_{n}^{\mathrm{e}} \\
& \boldsymbol{x}=\left[\begin{array}{cc}
\overline{\mathfrak{x}}(\zeta) & 0 \\
0 & \overline{\mathfrak{x}}(\zeta)
\end{array}\right] \\
& \underline{\mathbf{q}}_{n}^{\ell e}=\left[\begin{array}{llllllll}
u_{n}^{i g} & v_{n}^{i g} & w_{n}^{i g} & \frac{\mathrm{d} w_{n}^{i g}}{\mathrm{~d} S} & u_{n}^{i g} & v_{n}^{i g} & w_{n}^{i g} & \frac{\mathrm{d} w_{n}^{i g}}{\mathrm{~d} S}
\end{array}\right]^{T} ; \quad(g=1,2) \\
& \underline{\mathbf{q}}_{n}^{\mathrm{e}}=\left[\begin{array}{llllllll}
u_{r_{n}}^{i g} & u_{z_{n}}^{i g} & u_{\theta_{n}}^{i g} & \frac{\mathrm{d} w_{n}^{i g}}{\mathrm{~d} S} & u_{r_{n}}^{i g} & u_{z_{n}}^{i g} & u_{\theta_{n}}^{i g} & \frac{w_{n}^{i g}}{\mathrm{~d} S}
\end{array}\right]^{T} ; \quad(g=1,2)
\end{aligned}
$$

where $\mathbf{q}_{n}^{\text {le }}$ and $\mathbf{q}_{n}^{\mathrm{c}}$ are the vectors of the element nodal displacement amplitudes of order $16 \times 1$ in the local referential $(S, \theta, \xi)$ and system referential $(r, \theta, z)$, respectively, $\mathbf{L}$ a transformation matrix of order $16 \times 16$ which relates shell displacements with degrees of freedom of the element and system and $\overline{\mathfrak{N}}(\zeta)$ a matrix of shape functions of order $3 \times 8$ (Zienkiewicz, 1977).

Substituting eqns (31)-(34) into eqns (27) and (28) yields:

$$
\begin{aligned}
\underline{\varepsilon}^{\circ} & =\sum_{n=0}^{N} \mathbf{C}_{n} \mathbf{B}_{\mathrm{m}_{n}} \mathbf{L} \underline{\mathbf{q}}_{n}^{\mathrm{e}} \\
\underset{\sim}{\chi} & =\sum_{n=0}^{N} \mathbf{C}_{n} \mathbf{B}_{\mathrm{f}_{n}} \mathbf{L} \underline{q}_{n}^{\mathrm{e}}
\end{aligned}
$$

Using the orthogonality properties of trigonometric functions, considering also the applied loads expanded in terms of Fourier series and following a standard procedure via the principle of virtual work, the element stiffness matrix $\mathbf{K}_{n}^{\mathbf{e}}$, the element load vector ${\underset{\sim}{n}}_{n}^{e}$ and mass matrix $\mathbf{M}_{n}^{\mathfrak{e}}$ for the $n$th harmonic can be represented as:

$$
\begin{aligned}
& \mathbf{K}_{n}^{\mathbf{e}}=\mathbf{L}^{T}\left\{\int_{0}^{1}\left(\mathbf{B}_{\mathrm{m}_{n}}^{T} \overline{\mathbf{A}} \mathbf{B}_{\mathrm{m}_{n}}+\mathbf{B}_{\mathrm{m}_{n}}^{T} \overline{\mathbf{B}} \mathbf{B}_{\mathrm{f}_{n}}+\mathbf{B}_{\mathrm{f}_{n}}^{T} \overline{\mathbf{B}} \mathbf{B}_{\mathbf{m}_{n}}+\mathbf{B}_{\mathrm{f}_{n}}^{T} \overline{\mathbf{D}} \mathbf{B}_{\mathrm{f}_{n}}\right) r \ell \mathrm{d} \zeta\right\} \mathbf{L} \\
& \underline{p}_{n}^{\mathrm{e}}=\int_{0}^{2 \pi} \int_{0}^{1}\left(\boldsymbol{N}_{n} \mathbf{L}\right)_{\underline{\mathbf{f}}_{n}^{\mathrm{e}}}^{T^{\mathrm{e}}} r \mathrm{~d} \zeta \mathrm{d} \theta \\
& \mathbf{M}_{n}^{\mathrm{e}}=\sum_{k=1}^{N L} \rho_{k}\left(h_{k}-h_{k-1}\right) \int_{0}^{2 \pi} \int_{0}^{1}\left(\boldsymbol{N}_{n} \mathbf{L}\right)^{T}\left(\mathscr{N}_{n} \mathbf{L}\right) \ell \mathrm{d} \zeta \mathrm{d} \theta \\
& {[\overline{\mathbf{A}} ; \overline{\mathbf{B}} ; \overline{\mathbf{D}}]=\int_{0}^{2 \pi} \mathbf{C}_{n}^{T}[\mathbf{A} ; \mathbf{B} ; \mathbf{D}] \mathbf{C}_{n} \mathrm{~d} \theta}
\end{aligned}
$$

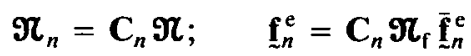

where $r$ is the radial coordinate, $\ell$ the length of generating line of the middle surface of the element, $\overline{\mathbf{f}}_{n}^{\mathrm{e}}$ the vector of surface loads amplitudes, $\boldsymbol{N}_{\mathrm{f}}$ is the matrix of linear shape functions of order $6 \times 16, \rho_{k}$ the mass per unit of volume for the $k$ th layer and $\zeta=S / \ell$ is the element local natural coordinate.

For simplified and symmetric ply configurations (Vinson and Sienakowski, 1986), the membrane and bending effects are decoupled and therefore the second and third terms of eqn (40) vanish.

The system equations for static and free vibrations are then obtained for the $n$th harmonic as:

$$
\begin{gathered}
\mathbf{K}_{n} \underline{\mathbf{q}}_{n}=\underline{\mathbf{Q}}_{n} \\
\mathbf{K}_{n} \underline{\mathbf{q}}_{\ell n}=\omega_{\ell n}^{2} \mathbf{M}_{n} \underline{\mathbf{q}}_{\ell n}
\end{gathered}
$$


where $\mathbf{K}_{n}, \mathbf{M}_{n}, \mathbf{Q}_{n}$ and $\mathbf{q}_{n}$ are, respectively, the system stiffness matrix, mass matrix, load vector and displacement, for the $n$th harmonic. For free vibrations $\mathbf{q}_{l n}$ is the system mode vector and $\omega_{\ell n}$ the natural frequency. After the introduction of boundary conditions the system equations can be easily solved for each harmonic for static or eigenvalue situations.

Equations (45) and (46) are uncoupled with respect to Fourier index, but for the general case of anisotropy of the material, there is coupling between the symmetric and anti-symmetric terms of the system displacement vector (Sheinman and Weissman, 1987). This coupling, which acts via the constitutive matrix, derives from the coefficients $A_{i 6}, B_{i 6}$ and $D_{i 6}(i=1,2)$ in eqn (43). For structures made of isotropic or orthotropic material, $\bar{A}, \bar{B}$ and $\bar{D}$ are tridiagonal banded and coupling vanishes (Sheinman and Weissman, 1987).

When the independent design variables are the orientation of the fibers of the plies or the vectorial distance from the middle surface to the upper surface of the $k$ th ply (Fig. 2), the vector of independent design variables $\mathbf{b}$ can be represented, respectively, as:

$$
\begin{aligned}
& \underline{\mathbf{b}}=\left[\begin{array}{lllll}
\boldsymbol{\alpha}_{1} & \ldots & \boldsymbol{\alpha}_{i} & \ldots & \boldsymbol{\alpha}_{N L}
\end{array}\right]^{T} \\
& \underline{\mathbf{b}}=\left[\begin{array}{lllll}
\mathbf{h}_{0} & \ldots & \mathbf{h}_{i} & \ldots & \mathbf{h}_{N L}
\end{array}\right]^{T} .
\end{aligned}
$$

The sensitivities of the element stiffness and mass matrices, eqns (40) and (42) with respect to perturbations in the above design variables are evaluated, respectively, as:

$$
\begin{gathered}
\frac{\partial \mathbf{K}_{n}^{\mathrm{e}}}{\partial \mathbf{b}_{i}}=\mathbf{L}^{T}\left\{\int_{0}^{1}\left(\mathbf{B}_{\mathrm{m}_{n}}^{T} \frac{\partial \overline{\mathbf{A}}}{\partial \mathbf{b}_{i}} \mathbf{B}_{\mathrm{m}_{n}}+\mathbf{B}_{\mathrm{m}_{n}}^{T} \frac{\partial \overline{\mathbf{B}}}{\partial \mathbf{b}_{i}} \mathbf{B}_{\mathrm{f}_{n}}+\mathbf{B}_{\mathrm{f}_{n}}^{T} \frac{\partial \overline{\mathbf{B}}}{\partial \mathbf{b}_{i}} \mathbf{B}_{\mathrm{m}_{n}}+\mathbf{B}_{\mathrm{f}_{n}}^{T} \frac{\partial \overline{\mathbf{D}}}{\partial \mathbf{b}_{i}} \mathbf{B}_{\mathrm{f}_{n}}\right) r \ell \mathrm{d} \zeta\right\} \mathbf{L} \\
\frac{\partial \mathbf{M}_{n}^{\mathrm{e}}}{\partial \mathbf{b}_{i}}=\left.\sum_{k=1}^{N L} \rho_{k} \frac{\partial}{\partial \mathbf{b}_{i}}\left(h_{k}-h_{k-1}\right)\right|_{0} ^{2 \pi} \int_{0}^{1}\left(\mathbf{N}_{n} \mathbf{L}\right)^{T}\left(\mathbf{N}_{n} \mathbf{L}\right) \ell r \mathrm{~d} \zeta \mathrm{d} \theta
\end{gathered}
$$

The differentiation of eqn (49) is accomplished by differentiating analytically eqn (26) with respect to design variables $\mathbf{b}_{i}$ defined by eqns (47) and (48), followed by matrix multiplication and numerical integration. Because of simplicity, for the chosen design variables, there is no need to use a symbolic manipulator.

For static problems the sensitivities of response:

$$
\psi(q, b)=\sum_{n=0}^{N} \psi_{n}(q, b)
$$

are evaluated through the technique of adjoint structure assuming that, for the $n$th harmonic, the structure satisfies the equilibrium equation;

$$
\mathbf{K}_{n} \lambda_{n}=\mathbf{z}_{n} .
$$

Where $\mathbf{z}_{n}=\partial \psi_{n} / \partial \mathbf{q}_{n}$ is the vector of adjoint forces and $\hat{\lambda}_{n}$ the system adjoint degrees of freedom.

The sensitivities of response can then be evaluated as:

$$
\begin{aligned}
\frac{\mathrm{d} \psi}{\mathrm{d} b_{i}} & =\sum_{n=0}^{N}\left\{\frac{\partial \psi_{n}}{\partial b_{i}}+\lambda_{n}^{I}\left(\frac{\partial \mathbf{Q}_{n}}{\partial b_{i}}-\frac{\partial \mathbf{K}_{n}}{\partial b_{i}} \underline{\mathbf{q}}_{n}\right)\right\} \\
& =\sum_{n=0}^{N}\left\{\frac{\partial \psi_{n}}{\partial b_{i}}+\sum_{c \in \mathrm{E}} \lambda_{n}^{\mathrm{e}^{r}}\left(\frac{\partial \underline{\mathbf{p}}_{n}^{\mathrm{e}}}{\partial b_{i}}-\frac{\partial \mathbf{K}_{n}^{\mathrm{e}}}{\partial b_{i}} \underline{\mathbf{q}}_{n}^{\mathrm{e}}\right)\right\}
\end{aligned}
$$

where $\partial \mathbf{K}_{n} / \partial b_{i}, \partial \mathbf{K}_{n}^{\mathrm{e}} / \partial b_{i}$ are the sensitivities of system and element stiffness matrix, $\partial \mathbf{Q}_{n} / \partial b_{i}, \partial \mathbf{p}_{n}^{\mathrm{c}} / \partial b_{i}$ the sensitivity of the system and element load vector, $\lambda_{n}^{\mathrm{c}}$ the element adjoint force and $\mathrm{E}$ is the set of elements $\mathrm{e}$ which are affected by the design variable $b_{i}$. 
When the function $\psi$ is the elastic strain energy:

$$
\psi=\sum_{n=0}^{N} \psi_{n}=\sum_{n=0}^{N} \frac{1}{2}{\underset{\mathbf{q}}{n}}_{n}^{T} \mathbf{K}_{n} \underline{\mathbf{q}}_{n}
$$

the sensitivity evaluated through eqn (53) can be shown to become:

$$
\frac{\mathrm{d} \psi}{\mathrm{d} b_{i}}=\sum_{n=0}^{N} \sum_{\mathrm{e} \in \mathrm{E}}\left\{\underline{\mathbf{q}}_{n}^{\mathbf{e}^{T}} \frac{\partial \underline{p}_{n}^{\mathrm{e}}}{\partial b_{i}}-\frac{1}{2}{\underset{q}{n}}_{n}^{\mathrm{e}^{T}} \frac{\partial \mathbf{K}_{n}^{\mathrm{e}}}{\partial b_{i}} \underline{\mathbf{q}}_{n}^{\mathrm{e}}\right\} .
$$

For free vibrations considering a particular frequency $\omega_{\ell_{n}}$, i.e. $\psi=\omega_{\ell_{n}}$, corresponding to mode of vibration $\mathbf{q}_{\ell_{n}}$, normalized through the relation ${\underset{q}{\ell_{n}}}_{T}^{T} \mathbf{M}_{n} \mathbf{q}_{\sim}{\underline{\ell_{n}}}_{n}=1$, the sensitivities of natural frequency are given by:

$$
\begin{aligned}
\frac{\partial \psi}{\partial b_{i}} & =\frac{1}{2 \omega_{\ell_{n}}} \underline{\mathbf{q}}_{\ell_{n}}^{T}\left(\frac{\partial \mathbf{K}_{n}}{\partial b_{i}}-\omega_{\ell_{n}}^{2} \frac{\partial \mathbf{M}_{n}}{\partial b_{i}}\right) \underline{\mathbf{q}}_{\ell_{n}} \\
& =\frac{1}{2 \omega_{\ell_{n}}} \sum_{\mathbf{e} \in \mathrm{E}} \mathbf{q}_{\vartheta_{n}}^{\mathbf{e}^{\mathrm{e}}}\left(\frac{\partial \mathbf{K}_{n}^{\mathrm{e}}}{\partial b_{i}}-\omega_{\ell_{n}}^{2} \frac{\partial \mathbf{M}_{n}^{\mathrm{e}}}{\partial b_{i}}\right) \underline{\mathbf{q}}_{\ell_{n}}^{\mathrm{e}}
\end{aligned}
$$

where $\partial \mathbf{M}_{n} / \partial b_{i}$ and $\partial \mathbf{M}_{n}^{\mathrm{e}} / \partial b_{i}$ are the system and element sensitivity matrices. From eqns (53), (55) and (56), one can see that the sensitivities of a function $\psi$ can be efficiently obtained at element level without the need of evaluating the system stiffness, mass and load vector sensitivities.

It is assumed that the mass matrix $\mathbf{M}_{n}^{\mathrm{e}}$, eqn (42), and the element load vector $\mathbf{p}_{n}^{\mathrm{e}}$, eqn (41), are independent of the ply orientation $\alpha_{i}$, yielding $\mathbf{M}_{n}^{\mathrm{e}} / \partial \boldsymbol{\alpha}_{i}=0$ and $\partial \underline{p}_{n}^{\mathrm{e}} / \partial \boldsymbol{\alpha}_{i}=\tilde{0}$.

\section{Semi-analytical method}

In this technique the vector of adjoint forces is obtained analytically and the gradients of eqns (53), (55) and (56), with terms of the type $\partial F / \partial b_{i}$, are evaluated by forward finite difference (FFD) through the approximation:

$$
\frac{\partial F}{\partial b_{i}} \approx \frac{F(\mathbf{b}+\Delta \mathbf{b})-F(\mathbf{b})}{\delta b_{i}}
$$

where $\Delta \mathbf{b}=\left[0, \ldots, \delta b_{i}, \ldots, 0\right]$ and $\delta b_{i}$ is a small perturbation.

For shell elements and shape design variables the sensitivities are known to be highly influenced by the perturbation used and wrong results can occur (Barthelemy et al., 1988; Barbosa et al., 1991; Mota Soares et al., 1994).

\section{Finite difference technique}

A global finite difference approach can be used as, for instance, forward finite difference (FFD). In this case the sensitivity of a constraint with respect to a change $\delta b_{i}$ in a design variable is given by:

$$
\frac{\mathrm{d} \psi}{\mathrm{d} b_{i}} \approx \frac{\psi\left(b_{1}, \ldots, b_{i}+\delta b_{i}, \ldots, b_{n}\right)-\psi(\mathbf{b})}{\delta b_{i}}
$$

which needs one extra structural analysis for each design variable.

\section{CONSTRAINTS}

\section{Displacement and stress constraint}

In a structural optimization problem the constraints are usually limits on displacements and/or stresses such as Tsai-Hill failure criterion (Tsai and Hahn, 1980) on multilayered composite materials or natural frequency constraints. The normalized form 
of an inequality optimization constraint is:

$$
\psi_{j}=\frac{G(b)_{j}}{G_{0_{j}}}-1 \leq 0
$$

where $G(b)_{j}$ and $G_{0}$ are the real and maximum admissible value of the $j$ th constraint, respectively. The adjoint forces for the $j$ th static constraint are obtained by expanding $G(b)_{j}$ by Fourier series.

For example, for a displacement constraint, the adjoint load vector becomes:

$$
\mathbf{z}_{j_{n}}=\left[\frac{\partial \psi_{j_{n}}}{\partial q_{1}} \cdots \frac{\partial \psi_{j_{n}}}{\partial q_{f}} \cdots \frac{\partial \psi_{j_{n}}}{\partial q_{p}}\right]^{T}=\left[0 \cdots \frac{C_{\mathrm{s}}}{G_{0_{j}}} \cdots \frac{C_{\mathrm{a}}}{G_{0_{j}}} \cdots 0\right]^{T}
$$

where $p$ is the total number of degrees of freedom and $C_{\mathrm{s}}=(\cos n \theta$ or $\sin n \theta)$ and $C_{\mathrm{a}}=(\sin n \theta$ or $\cos n \theta)$ related to the corresponding degree of freedom.

For the Tsai-Hill failure criterion the constraint is:

$$
\psi_{j}=\sum_{n=0}^{N}\left\{\left(\frac{\sigma_{11_{n}}}{\sigma_{11_{\mathrm{f}}}}\right)^{2}+\left(\frac{\sigma_{22_{n}}}{\sigma_{22_{\mathrm{f}}}}\right)^{2}+\left(\frac{\sigma_{12_{n}}}{\sigma_{22_{\mathrm{f}}}}\right)^{2}-\left(\frac{\sigma_{11_{n}} \sigma_{22_{n}}}{\sigma_{11_{\mathrm{f}}}^{2}}\right)\right\}-1 \leq 0
$$

where $\sigma_{11_{\mathrm{f}}}$ and $\sigma_{22_{\mathrm{f}}}$ are the tensile or compressive yield stresses of each ply in material axes $\left(x_{1}, x_{2}, \xi\right)$, while $\sigma_{12_{\mathrm{f}}}$ is the yielding shear stress. The stresses $\sigma_{n}^{*}=\left[\begin{array}{lll}\sigma_{11_{n}} & \sigma_{22_{n}} & \sigma_{12_{n}}\end{array}\right]^{T}$ for the $n$th harmonic are related with the element stresses $\sigma_{n}$ through $\sigma_{n}^{*}=T_{k} \sigma_{n}$, where $T_{k}$ is a rotation matrix (Vinson and Sienakowski, 1986) and $\sigma_{n}=\left[\begin{array}{lll}\sigma_{\theta \theta_{n}} & \sigma_{S s_{n}} & \sigma_{S \theta_{n}}\end{array}\right]^{T}$ is the vector of stress components in shell axes $(S, \theta, \xi)$ for the $n$th harmonic, ply $k$ and Gaussian point $(j)$ of element (e).

The vector of adjoint forces, as well as the term $\partial \psi_{n} / \partial b_{i}$ of eqn (53), is evaluated for $n$th harmonic, $k$ th ply and element (e), by differentiating eqn (61) analytically.

\section{Natural frequency constraint}

A constraint in the natural frequency of mode $\ell$ can be easily evaluated once the eigenvalue problem is solved. Considering a normalized constraint of the type:

$$
\psi_{j}=1-\frac{\omega_{\ell}}{\omega_{0}} \leq 0
$$

The sensitivity of eqn (62) is evaluated as:

$$
\frac{\partial \psi_{j}}{\mathrm{~d} b_{i}}=-\frac{1}{2 \omega_{0} \omega_{\ell_{n}}} \sum_{\mathrm{e} \in \mathrm{E}} \mathbf{q}_{\ell_{n}}^{\mathrm{e}^{T}}\left(\frac{\partial \mathbf{K}_{n}^{\mathrm{e}}}{\partial b_{i}}-\omega_{\ell_{n}}^{2} \frac{\partial \mathbf{M}_{n}^{\mathrm{e}}}{\partial b_{i}}\right) \mathbf{q}_{\ell_{n}}^{\mathrm{e}}
$$

where $\omega_{0}$ is the limiting natural frequency for mode $\ell$.

\section{OPTIMAL DESIGN}

The objective is to find the fiber direction $\alpha_{i}$ of each ply that minimizes a displacement of a specified nodal point of the discrete finite element model or minimizes the elastic strain energy or maximizes the natural frequency. The optimization can be stated as:

$$
\min \Psi^{i}(b)
$$

subjected to:

$$
b_{i}^{\ell} \leq b_{i} \leq b_{i}^{u} \quad i=1,2, \ldots, n_{\mathrm{d}}
$$

where $\Psi^{i}$ is the objective function, $b_{i}^{\ell}$ and $b_{i}^{u}$ are the lower and upper limiting bounds of the design variables and $n_{\mathrm{d}}$ the total number of angle design variables. For the maximization of a specified natural frequency $\Psi^{i}=-\omega_{\ell_{n}}$. 
The above procedure can be followed by the minimization of the volume of the shell material, using the vectorial distances as design variables, subject to constraints of displacements, Tsai-Hill failure criterion and natural frequency of a chosen mode. The optimization problem can be stated as:

$$
\min \Psi^{i i}(b)
$$

subjected to:

$$
\begin{array}{ll}
\psi_{j}(q, b) \leq 0 & j=1, \ldots, m \\
b_{i}^{\ell} \leq b_{i} \leq b_{i}^{u} & i=1, \ldots, n_{\mathrm{h}}
\end{array}
$$

where $\Psi^{i i}$ is the objective function (volume of the shell material), $m$ the number of constraint equations and $n_{\mathrm{h}}$ is total number of vectorial distances. The above procedures are being implemented as a two stage iterative algorithm.

The nonlinear mathematical problems are solved by Davidson-Fletcher-Powel variable method and modified feasible directions method for unconstrained (only side constraints) and constrained problems, respectively (Vanderplaats, 1984, 1987).

\section{APPLICATIONS}

The discrete model developed has been applied to the structural and sensitivity analyses and optimal design of two typical test cases of a conical and a cylindrical shell.

\section{Conical shell}

A three layered frustum-conical shell clamped at both ends, with stacking sequences $\left[\alpha / 0^{\circ} / \alpha\right]$ and $\left[\alpha / 0^{\circ} /-\alpha\right]$ is analyzed with regard to dynamical behavior (natural frequencies). The material data is:

$E_{1}=206.9 \mathrm{GPa}$ (Young's modulus in the fibers directions)

$E_{2}=18.8 \mathrm{GPa}$ (Young's modulus perpendicular to the fibers)

$G_{12}=4.48 \mathrm{GPa}$ (Shear modulus); $v_{12}=0.28$ (Poisson's ratio)

$h_{\mathrm{p}}=0.000167 \mathrm{~m}$ (thickness of each layer) and $\rho_{k}=2048 \mathrm{~kg} \cdot \mathrm{m}^{-3}$ (mass density).

The shell geometry is: height).

$r_{\mathrm{u}}=0.1905 \mathrm{~m}$ (upper radius); $r_{\mathrm{i}}=0.381 \mathrm{~m}$ (lower radius); $L=0.381 \mathrm{~m}$ (shell

A discrete model with 26 ring elements has been used. The eigen frequencies analyses are in close agreement with a similar study carried out by Sheinman and Weissman (1987), as shown in Table 1, for the fundamental natural frequency.

Table 1. Conical shell. Natural frequencies $(\mathrm{Hz})$

\begin{tabular}{cccccc}
\hline & \multicolumn{2}{c}{ Present } & & \multicolumn{2}{c}{ Sheinman and Weissman } \\
\cline { 2 - 3 } \cline { 5 - 6 } Orientation & $(1)$ & $(2)$ & & $(1)$ & $(2)$ \\
\hline $0^{\circ} / 0^{\circ} / 0^{\circ}$ & $180.0(11)$ & $180.0(11)$ & & $179.8(11)$ & $179.8(11)$ \\
$15^{\circ} / 0^{\circ} / 15^{\circ}$ & $235.2(12)$ & $218.7(12)$ & & $235.1(12)$ & $221.4(12)$ \\
$30^{\circ} \% 0^{\circ} / 30^{\circ}$ & $278.7(13)$ & $263.8(12)$ & & $281.8(12)$ & $262.1(12)$ \\
$45^{\circ} / 0^{\circ} / 45^{\circ}$ & $314.2(11)$ & $293.5(11)$ & & $317.0(11)$ & $288.7(11)$ \\
$60^{\circ} / 0^{\circ} / 60^{\circ}$ & $344.5(10)$ & $291.3(9)$ & & $366.8(10)$ & $288.6(9)$ \\
$75^{\circ} / 0^{\circ} / 75^{\circ}$ & $327.1(9)$ & $269.9(8)$ & & $325.9(9)$ & $268.4(8)$ \\
$90^{\circ} / 0^{\circ} / 90^{\circ}$ & $256.7(7)$ & $256.7(7)$ & & $256.3(7)$ & $256.3(7)$ \\
$15^{\circ} / 0^{\circ} /-15^{\circ}$ & $234.9(13)$ & $231.9(13)$ & & $235.1(12)$ & $230.5(13)$ \\
$30^{\circ} / 0^{\circ} /-30^{\circ}$ & $278.7(13)$ & $254.6(13)$ & & $281.8(12)$ & $254.3(13)$ \\
$45^{\circ} / 0^{\circ} /-45^{\circ}$ & $314.2(11)$ & $255.2(13)$ & & $317.1(11)$ & $260.5(12)$ \\
$60^{\circ} / 0^{\circ} /-60^{\circ}$ & $344.5(10)$ & $264.9(12)$ & & $344.8(10)$ & $268.9(12)$ \\
$75^{\circ} / 0^{\circ} /-75^{\circ}$ & $327.1(9)$ & $275.0(10)$ & $325.9(9)$ & $276.1(10)$ \\
\hline
\end{tabular}

(1)-Coupling disregard: (2)-Coupling allowed.

() Number in parentheses indicates circumferential mode. 
Table 2. Conical shell. Sensitivities of fundamental frequency $\partial \omega_{12}^{1} / \partial \alpha_{i}$

\begin{tabular}{lccc}
\hline & $\alpha_{1}=15^{\circ}$ & $\alpha_{2}=0^{\circ}$ & $\alpha_{3}=15^{\circ}$ \\
\hline Analytical & $-0.10222 \times 10^{4}$ & $0.56199 \times 10^{3}$ & $-0.22898 \times 10^{3}$ \\
SA $\delta \alpha_{i}=0.001^{\circ}$ & $-0.10224 \times 10^{4}$ & $0.56196 \times 10^{3}$ & $-0.22901 \times 10^{3}$ \\
GFD $\delta \alpha_{i}=0.001^{\circ}$ & $-0.10223 \times 10^{4}$ & $0.56198 \times 10^{3}$ & $-0.22898 \times 10^{3}$ \\
\hline
\end{tabular}

Table 3. Conical shell. Sensitivities of fundamental frequency $\partial \omega_{13}^{1} / \partial \alpha_{i}$

\begin{tabular}{lccc}
\hline & $\alpha_{1}=45^{\circ}$ & $\alpha_{2}=0^{\circ}$ & $\alpha_{3}=-45^{\circ}$ \\
\hline Analytical & $0.425353 \times 10^{2}$ & $-0.458760 \times 10^{3}$ & $0.226957 \times 10^{3}$ \\
SA $\delta \alpha_{i}=0.001^{\circ}$ & $0.424878 \times 10^{2}$ & $-0.458776 \times 10^{3}$ & $0.226930 \times 10^{3}$ \\
GFD $\delta \alpha_{i}=0.001^{\circ}$ & $0.425327 \times 10^{2}$ & $-0.458764 \times 10^{3}$ & $0.226950 \times 10^{3}$ \\
\hline
\end{tabular}

The coupling effects between the symmetric and anti-symmetric modes which take place through the constitutive matrices $\overline{\mathbf{A}}, \overline{\mathbf{B}}$ and $\overline{\mathbf{D}}$ (eqn (43)) can be seen with regard to alterations in the values of the natural frequencies and mode shape in the circumferential direction.

In Tables 2 and 3 the natural frequencies sensitivities with respect to ply orientation $\alpha_{i}$, for the lay-ups $\left[\alpha_{1} / \alpha_{2} / \alpha_{3}\right]=\left[15^{\circ} / 0^{\circ} / 15^{\circ}\right]$ and $\left[45^{\circ} / 0^{\circ} /-45^{\circ}\right]$, which correspond to the fundamental natural frequencies $f_{12}^{1}=235.2 \mathrm{~Hz}$ and $f_{13}^{1}=255.2 \mathrm{~Hz}$, respectively, are evaluated analytically, semi-analytically (SA) and by global finite diffrences (GFD) with a good agreement between the results of the three techniques.

The shell structure is then optimized for the maximation of $f_{12}^{1}$ in accordance with eqns (64) and (65), yielding for the optimal design

$$
f_{12}^{1}=370.37 \mathrm{~Hz}, \quad\left[\alpha / 0^{\circ} / \alpha\right]=\left[90^{\circ} / 0^{\circ} / 90^{\circ}\right],
$$

when coupling is allowed and

$$
f_{12}^{1}=399.87 \mathrm{~Hz}, \quad\left[\alpha / 0^{\circ} / \alpha\right]=\left[72.65^{\circ} / 0^{\circ} / 72.65^{\circ}\right],
$$

when coupling is disregarded. In Fig. 4 a distribution of lowest natural frequency versus fiber orientation angle $\alpha$ shows an excellent agreement with the optimal solutions.

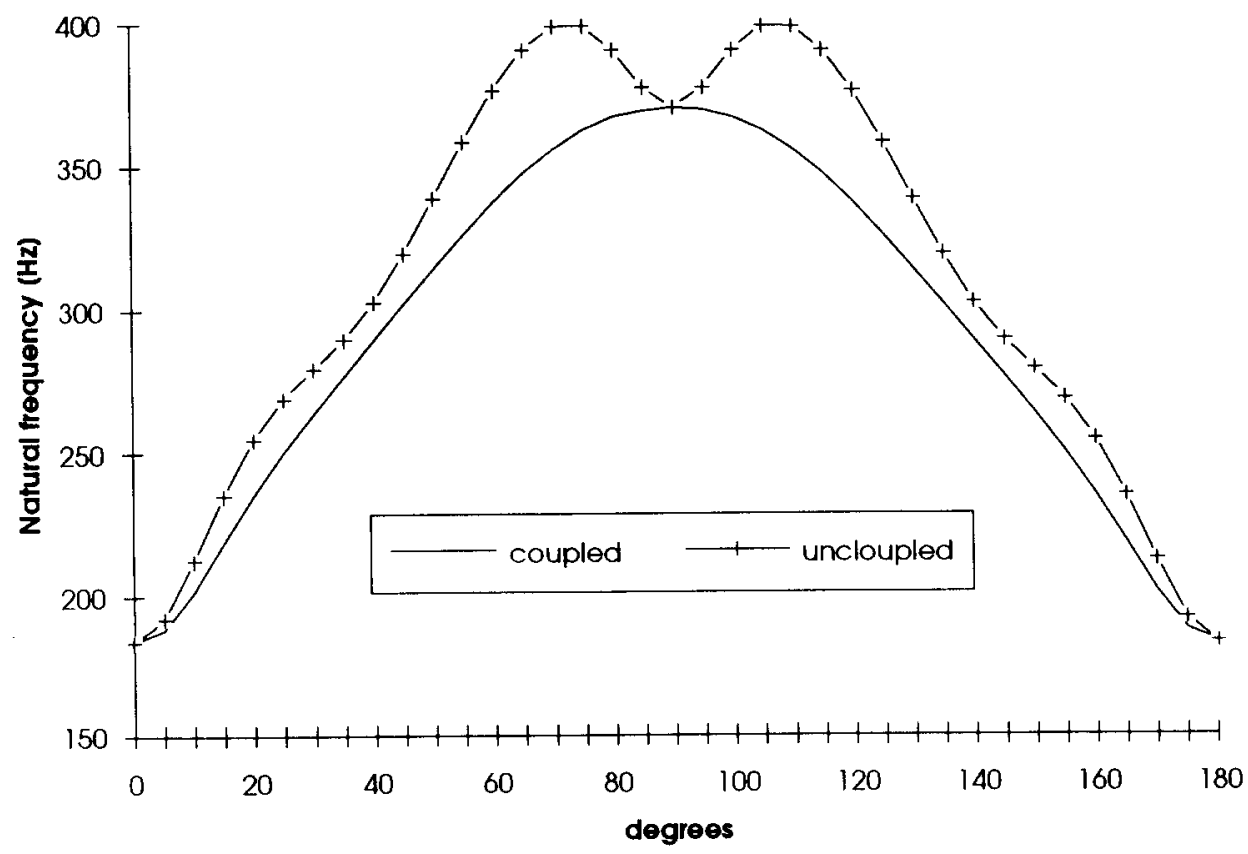

Fig. 4. Natural frequency versus ply angle $\alpha$ (lay-up $\left[\alpha / 0^{\circ} / \alpha\right]$ ). 
When the coupling between symmetric and antisymmetric modes is disregarded two optimal solutions are obtained, $\alpha=72.65^{\circ}$ and $\alpha=107.65^{\circ}$ depending on the initial guess. It is also observed that with coupling between symmetric and anti-symmetric modes one obtains an absolute maximum and the solution as expected is more conservative.

\section{Cylindrical shell}

A cylinder shell with 12 plies presented in Fig. 5 is considered, with a radius $R=0.25 \mathrm{~m}$ and length $L=2.5 \mathrm{~m}$. The shell is assumed simply supported at both ends, i.e. $u, v, w=0$. The material properties are $E_{1}=38.6 \mathrm{GPa}, E_{2}=8.27 \mathrm{GPa}, G_{12}=4.14 \mathrm{GPa}, v=0.26$. The initial design thickness of each ply is $e_{k}=0.1 \times 10^{-3} \mathrm{~m}$.

The cylinder is assumed $25 \%$ filled, i.e. $\left(\varphi=66.2^{\circ}\right)$ with a liquid of density $\rho=5700 \mathrm{~kg} / \mathrm{m}^{3}$, hence the radial pressure loading is represented as:

$$
\begin{array}{ll}
p_{R}=-\rho R(\cos \theta-\cos \varphi) & \text { for } \theta \leq \varphi \\
p_{R}=0 & \text { for } \theta>\varphi \\
p_{\theta}=p_{z}=0 & \text { for all } \theta .
\end{array}
$$

This loading is expanded considering seven harmonics of Fourier series. To compare the structural analyses with an alternative closed-form solution (Tooth et al., 1988) the problem has been solved using the symmetric degrees of freedom only (uncoupled).

To study the influence of the fibers in the axial and circumferential directions the shell has first been analyzed for the following ply lay-ups:
(a) $\left[90^{\circ}\right]_{12}$;
(b) $\left[\left(0^{\circ} / 90^{\circ}\right)_{3}\right]_{s}$;
(c) $\left[0^{\circ}\right]_{12}$

using a discretization of 50 equal ring shell elements.

The radial and circumferential displacement distribution versus circumferential coordinate $\theta$ at $Z=L / 2$ shown in Figs 6 and 7 have a very good agreement with the results obtained by Tooth et al. (1988).

For lay-up (b), the sensitivities of maximum displacement and elastic strain energy, with respect to design variables of ply angles (eqn (47)) and vectorial distances (eqn (48)) are evaluated analytically, semi-analytically and by global forward finite difference, with a perturbation of $\alpha_{i}=0.0001^{\circ}$ and $\delta h_{i}=10^{-5} h$ ( $h=$ total thickness). It can be demonstrated that for $\alpha_{k}=\pi j / 2(j=0,1,2, \ldots)$ only terms $\left(\partial \bar{Q}_{16}\right)_{k} / \partial \alpha_{k}$ and $\left(\partial \bar{Q}_{26}\right)_{k} / \partial \alpha_{k}$ are different from zero. Hence the expected discrete analytical solution $\partial w / \partial \alpha_{k}$ should be zero because only symmetric degrees of freedom are considered. From Tables 4 and 5 it can be observed that the semi-analytical solution and global finite difference results compare very favorably with the analytical discrete model.

The objective of the design is the minimization of the volume of the cylinder material in accordance with eqns (66)-(68), using the vectorial distances as design variables and lay-up $\left[\left(0^{\circ} / 90^{\circ}\right)_{3}\right]_{S}$. The following constraints were imposed:

$$
\begin{array}{ll}
q_{0}=1.0 \times 10^{-3} \mathrm{~m} & \text { (maximum displacement) } \\
0 \leq e_{i}<0.11 \times 10^{-3} \mathrm{~m} & \text { (thickness side constraints) where } e_{i}=h_{i}+h_{i-1} .
\end{array}
$$

The volume of the material for the initial design is $V=4.71239 \times 10^{-3} \mathrm{~m}^{3}$ and the maximum displacement for this initial design is $q_{\max }=0.783 \times 10^{-3} \mathrm{~m}$.
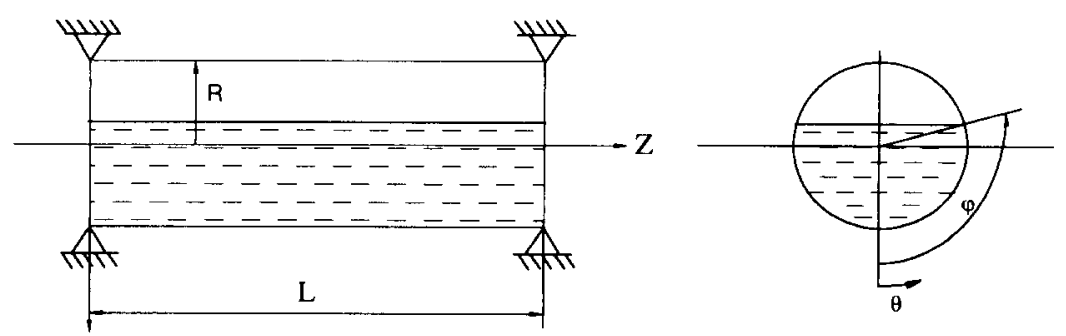

Fig. 5. Cylindrical shell. 


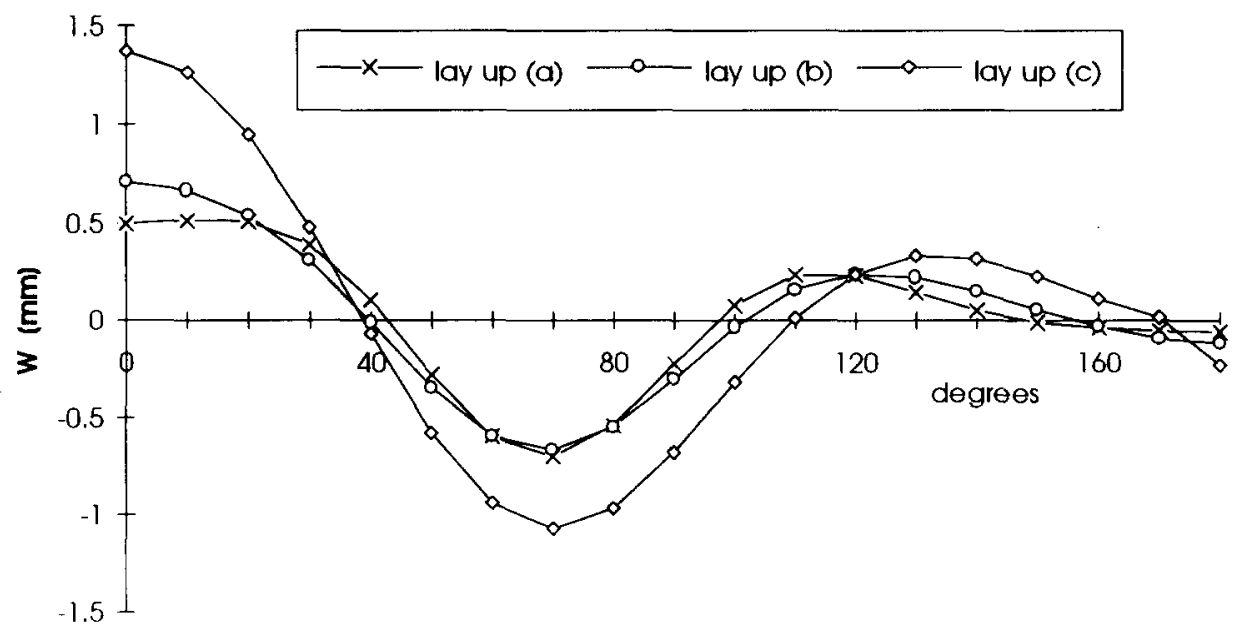

Fig. 6. Radial displacement versus circumferential angle $\theta$. Lay-ups (a) $\left[90^{\circ}\right]_{12}$; (b) $\left[\left(0^{\circ} / 90^{\circ}\right)_{3}\right]_{s} ;$ (c) $\left[0^{\circ}\right]_{12}$.

The optimal design, whose results are shown in Table 6, have been obtained in 10 functions evaluation and 2 gradients evaluation. This optimal design corresponds to a volume $V=3.723 \times 10^{-3} \mathrm{~m}^{3}$ and a maximum displacement $q_{\max }=0.966 \times 10^{-3} \mathrm{~m}$. This value has activated the constraint since it is within the interval $q_{0}-\varepsilon, q+\varepsilon$ defined by the user $\left(\varepsilon=0.035 \times 10^{-3} \mathrm{~m}\right)$ in program ADS. After the optimization process a $21 \%$ volume reduction was achieved.

To validate the Tsai-Hill stress sensitivities and displacement sensitivities with a concentrated load, a similar analysis has been carried out, assuming a 12 ply lay-up $\left[\left(0^{\circ} / 90^{\circ}\right)_{3}\right]_{s}$ with a total thickness of $h=0.01667 \mathrm{~m}$. The yielding strengths considered were $\sigma_{11_{\mathrm{f}}}=1430 \mathrm{MPa}, \sigma_{22_{\mathrm{f}}}=230 \mathrm{MPa}$ and $\sigma_{12_{\mathrm{f}}}=40 \mathrm{MPa}$. The load $P=5 \mathrm{kN}$ is applied at $Z=L / 2$ and $\theta=0$. A discrete model with 50 ring elements was used for the analysis and 50 harmonic terms of Fourier series were considered. The maximum displacement (at $Z=L / 2, \theta=0$ ) for the present model is $0.571 \times 10^{-3} \mathrm{~m}$, which compares very favorably with the value of $0.572 \times 10^{-3} \mathrm{~m}$ obtained using a general discrete model, based on discrete Kirchhoff theory, modeled with 1920 triangular elements (Correia, 1990).

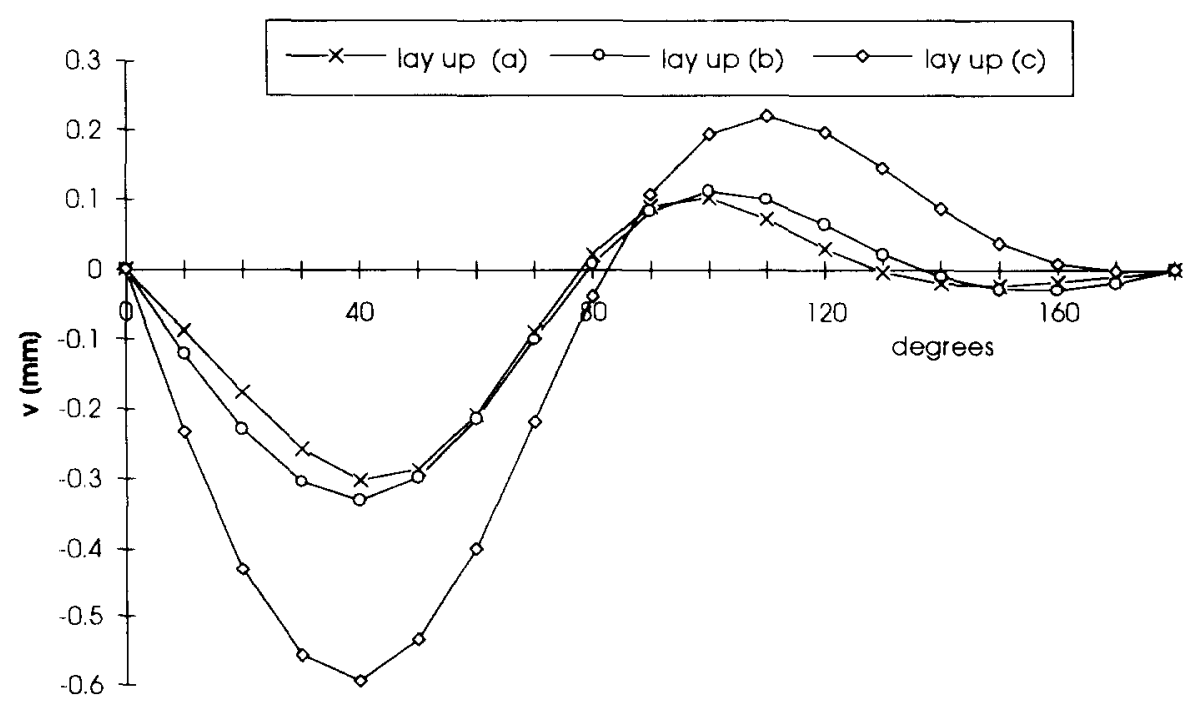

Fig. 7. Circumferential displacement versus circumferential angle $\theta$. Lay-ups (a) $\left[90^{\circ}\right]_{12}$; (b) $\left[\left(0^{\circ} / 90^{\circ}\right)_{3}\right]_{s}$; (c) $\left[0^{\circ}\right]_{12}$. 
Table 4. Cylindrical shell. Sensitivity of ply angle $\alpha_{i}$

\begin{tabular}{|c|c|c|c|}
\hline & & Displacement & Strain energy \\
\hline$\alpha_{0}$ & $\begin{array}{l}\text { Analytical } \\
\text { SA } \\
\text { GFD }\end{array}$ & $\begin{array}{l}0.0 \\
-0.807158 \times 10^{-9} \\
-0.799429 \times 10^{-9}\end{array}$ & $\begin{array}{l}0.0 \\
-0.238530 \times 10^{-6} \\
-0.237987 \times 10^{-6}\end{array}$ \\
\hline$\alpha_{1}$ & $\begin{array}{l}\text { Analytical } \\
\text { SA } \\
\text { GFD }\end{array}$ & $\begin{array}{l}\quad 0.0 \\
-0.278742 \times 10^{-8} \\
-0.279634 \times 10^{-8}\end{array}$ & $\begin{array}{l}\quad 0.0 \\
-0.349440 \times 10^{-6} \\
-0.348830 \times 10^{-6}\end{array}$ \\
\hline$\alpha_{2}$ & $\begin{array}{l}\text { Analytical } \\
\text { SA } \\
\text { GFD }\end{array}$ & $\begin{array}{l}0.0 \\
-0.868701 \times 10^{-9} \\
-0.856779 \times 10^{-9}\end{array}$ & $\begin{array}{l}\quad 0.0 \\
-0.244428 \times 10^{-6} \\
-0.243594 \times 10^{-6}\end{array}$ \\
\hline$\alpha_{3}$ & $\begin{array}{l}\text { Analytical } \\
\text { SA } \\
\text { GFD }\end{array}$ & $\begin{array}{l}0.0 \\
-0.278506 \times 10^{-8} \\
-0.278048 \times 10^{-8}\end{array}$ & $\begin{array}{l}\quad 0.0 \\
-0.386839 \times 10^{-6} \\
-0.388634 \times 10^{-6}\end{array}$ \\
\hline$\alpha_{4}$ & $\begin{array}{l}\text { Analytical } \\
\text { SA } \\
\text { GFD }\end{array}$ & $\begin{array}{l}0.0 \\
-0.922573 \times 10^{-9} \\
-0.914968 \times 10^{-9}\end{array}$ & $\begin{array}{l}\quad 0.0 \\
-0.248399 \times 10^{-6} \\
-0.247706 \times 10^{-6}\end{array}$ \\
\hline$\alpha_{5}$ & $\begin{array}{l}\text { Analytical } \\
\text { SA } \\
\text { GFD }\end{array}$ & $\begin{array}{l}0.0 \\
-0.284476 \times 10^{-8} \\
-0.284227 \times 10^{-8}\end{array}$ & $\begin{array}{l}\quad 0.0 \\
-0.406602 \times 10^{-6} \\
-0.406183 \times 10^{-6}\end{array}$ \\
\hline$\alpha_{6}$ & $\begin{array}{l}\text { Analytical } \\
\text { SA } \\
\text { GFD }\end{array}$ & $\begin{array}{l}0.0 \\
-0.289244 \times 10^{-8} \\
-0.288274 \times 10^{-8}\end{array}$ & $\begin{array}{l}\quad 0.0 \\
-0.408670 \times 10^{-6} \\
-0.408008 \times 10^{-6}\end{array}$ \\
\hline$\alpha_{7}$ & $\begin{array}{l}\text { Analytical } \\
\text { SA } \\
\text { GFD }\end{array}$ & $\begin{array}{l}0.0 \\
-0.103660 \times 10^{-8} \\
-0.103021 \times 10^{-8}\end{array}$ & $\begin{array}{l}\quad 0.0 \\
-0.253991 \times 10^{-6} \\
-0.253270 \times 10^{-6}\end{array}$ \\
\hline$\alpha_{8}$ & $\begin{array}{l}\text { Analytical } \\
\text { SA } \\
\text { GFD }\end{array}$ & $\begin{array}{l}0.0 \\
-0.303718 \times 10^{-8} \\
-0.303362 \times 10^{-8}\end{array}$ & $\begin{array}{l}0.0 \\
-0.399126 \times 10^{-6} \\
-0.398679 \times 10^{-6}\end{array}$ \\
\hline$\alpha_{9}$ & $\begin{array}{l}\text { Analytical } \\
\text { SA } \\
\text { GFD }\end{array}$ & $\begin{array}{l}0.0 \\
-0.111683 \times 10^{-8} \\
-0.110683 \times 10^{-8}\end{array}$ & $\begin{array}{l}\quad 0.0 \\
-0.256017 \times 10^{-6} \\
-0.255270 \times 10^{-6}\end{array}$ \\
\hline$\alpha_{10}$ & $\begin{array}{l}\text { Analytical } \\
\text { SA } \\
\text { GFD }\end{array}$ & $\begin{array}{l}0.0 \\
-0.323106 \times 10^{-8} \\
-0.322858 \times 10^{-8}\end{array}$ & $\begin{array}{l}\quad 0.0 \\
-0.369282 \times 10^{-6} \\
-0.368966 \times 10^{-6}\end{array}$ \\
\hline$\alpha_{11}$ & $\begin{array}{l}\text { Analytical } \\
\text { SA } \\
\text { GFD }\end{array}$ & $\begin{array}{l}0.0 \\
-0.121288 \times 10^{-8} \\
-0.120397 \times 10^{-8}\end{array}$ & $\begin{array}{l}\quad 0.0 \\
-0.257979 \times 10^{-6} \\
-0.257342 \times 10^{-6}\end{array}$ \\
\hline
\end{tabular}

SA; GFD: $\delta \alpha_{i}=0.001^{\circ}$.

Tables 7 and 8 show that the displacements and stress sensitivities evaluated using the proposed analytical or semi-analytical procedure or using global finite differences with a perturbation of $\alpha_{i}=0.001^{\circ}$ and $\delta h_{i}=10^{-5} h$ give almost identical results.

On the above applications it has been found that the analytical sensitivities (A) are very efficient with regard to CPU time when compared with semi-analytical (SA) and global finite difference (GFD). These CPU ratios are about $\mathrm{SA} / \mathrm{A}=1.2$ and $\mathrm{GFD} / \mathrm{A}=1.5$.

Finally, the structural analyses results shown in this paper, and elsewhere by Sheinman and Weissman (1987), and the sensitivity results here presented for anisotropic thin axisymmetric structures, and elsewhere by Barbosa et al. (1991) and Mota Soares et al. (1994), for isotropic structures, desmonstrate the simplicity and efficiency of the proposed discrete model.

\section{CONCLUSIONS}

A discrete finite element model based on a two node frustum-cone finite element with 16 degrees of freedom formulated using the Love-Kirchhoff theory has been developed to calculate the sensitivities of response with respect to changes in design variables for arbitrary shells of revolution made of layered composite materials taking into consideration the coupling effect, due to anisotropy, between symmetric and antisymmetric degrees of freedom. 
Table 5. Cylindrical shell. Sensitivity of maximum displacement $\partial w / \partial h_{i}$ and elastic strain energy $\partial U / \partial h_{i}$

\begin{tabular}{|c|c|c|c|}
\hline & & Displacement & Strain energy \\
\hline$h_{0}$ & $\begin{array}{l}\text { Analytical } \\
\text { SA } \\
\text { GFD }\end{array}$ & $\begin{array}{l}0.91758 \\
0.91770 \\
0.91772\end{array}$ & $\begin{array}{l}0.99228 \times 10^{2} \\
0.99237 \times 10^{2} \\
0.99241 \times 10^{2}\end{array}$ \\
\hline$h_{1}$ & $\begin{array}{l}\text { Analytical } \\
\text { SA } \\
\text { GFD }\end{array}$ & $\begin{array}{l}-0.56587 \\
-0.56590 \\
-0.56591\end{array}$ & $\begin{array}{l}-0.27516 \times 10^{2} \\
-0.27514 \times 10^{2} \\
-0.27512 \times 10^{2}\end{array}$ \\
\hline$h_{2}$ & $\begin{array}{l}\text { Analytical } \\
\text { SA } \\
\text { GFD }\end{array}$ & $\begin{array}{l}0.55446 \\
0.55447 \\
0.55446\end{array}$ & $\begin{array}{l}0.33710 \times 10^{2} \\
0.33709 \times 10^{2} \\
0.33709 \times 10^{2}\end{array}$ \\
\hline$h_{3}$ & $\begin{array}{l}\text { Analytical } \\
\text { SA } \\
\text { GFD }\end{array}$ & $\begin{array}{l}-0.54643 \\
-0.54641 \\
-0.54639\end{array}$ & $\begin{array}{l}-0.38565 \times 10^{2} \\
-0.38562 \times 10^{2} \\
-0.38561 \times 10^{2}\end{array}$ \\
\hline$h_{4}$ & $\begin{array}{l}\text { Analytical } \\
\text { SA } \\
\text { GFD }\end{array}$ & $\begin{array}{l}0.54177 \\
0.54178 \\
0.54183\end{array}$ & $\begin{array}{l}0.42081 \times 10^{2} \\
0.42086 \times 10^{2} \\
0.42089 \times 10^{2}\end{array}$ \\
\hline$h_{5}$ & $\begin{array}{l}\text { Analytical } \\
\text { SA } \\
\text { GFD }\end{array}$ & $\begin{array}{l}-0.54049 \\
-0.54044 \\
-0.54043\end{array}$ & $\begin{array}{l}-0.44260 \times 10^{2} \\
-0.44258 \times 10^{2} \\
-0.44255 \times 10^{2}\end{array}$ \\
\hline$h_{6}$ & $\begin{array}{l}\text { Analytical } \\
\text { SA } \\
\text { GFD }\end{array}$ & $\begin{array}{c}0.0 \\
0.21786 \times 10^{-10} \\
0.83544 \times 10^{-10}\end{array}$ & $\begin{array}{l}0.0 \\
0.65432 \times 10^{-8} \\
0.52038 \times 10^{-8}\end{array}$ \\
\hline$h_{7}$ & $\begin{array}{l}\text { Analytical } \\
\text { SA } \\
\text { GFD }\end{array}$ & $\begin{array}{l}0.54805 \\
0.54807 \\
0.54812\end{array}$ & $\begin{array}{l}0.44600 \times 10^{2} \\
0.44603 \times 10^{2} \\
0.44605 \times 10^{2}\end{array}$ \\
\hline$h_{8}$ & $\begin{array}{l}\text { Analytical } \\
\text { SA } \\
\text { GFD }\end{array}$ & $\begin{array}{l}-0.55689 \\
-0.55688 \\
-0.55683\end{array}$ & $\begin{array}{l}-0.42763 \times 10^{2} \\
-0.42760 \times 10^{2} \\
-0.42755 \times 10^{2}\end{array}$ \\
\hline$h_{9}$ & $\begin{array}{l}\text { Analytical } \\
\text { SA } \\
\text { GFD }\end{array}$ & $\begin{array}{l}0.56910 \\
0.56911 \\
0.56915\end{array}$ & $\begin{array}{l}0.39587 \times 10^{2} \\
0.39590 \times 10^{2} \\
0.39591 \times 10^{2}\end{array}$ \\
\hline$h_{10}$ & $\begin{array}{l}\text { Analytical } \\
\text { SA } \\
\text { GFD }\end{array}$ & $\begin{array}{l}-0.58469 \\
-0.58469 \\
-0.58468\end{array}$ & $\begin{array}{l}-0.35072 \times 10^{2} \\
-0.35070 \times 10^{2} \\
-0.35062 \times 10^{2}\end{array}$ \\
\hline$h_{11}$ & $\begin{array}{l}\text { Analytical } \\
\text { SA } \\
\text { GFD }\end{array}$ & $\begin{array}{l}0.60365 \\
0.60363 \\
0.60362\end{array}$ & $\begin{array}{l}0.29219 \times 10^{2} \\
0.29223 \times 10^{2} \\
0.29224 \times 10^{2}\end{array}$ \\
\hline$h_{12}$ & $\begin{array}{l}\text { Analytical } \\
\text { SA } \\
\text { GFD }\end{array}$ & $\begin{array}{l}-0.92754 \\
-0.92750 \\
-0.92740\end{array}$ & $\begin{array}{l}-0.98635 \times 10^{2} \\
-0.98625 \times 10^{2} \\
-0.98622 \times 10^{2}\end{array}$ \\
\hline
\end{tabular}

SA; GFD: $\delta h_{i}=10^{-5} h$.

Table 6. Cylindical shell. Optimal solution. Vectorial distances $(\mathrm{m})$

\begin{tabular}{lcc}
\hline & Initial & Final \\
\hline$h_{0}$ & $-0.60 \times 10^{-3}$ & $-0.4740 \times 10^{-3}$ \\
$h_{1}$ & $-0.50 \times 10^{-3}$ & $-0.4740 \times 10^{-3}$ \\
$h_{2}$ & $-0.40 \times 10^{-3}$ & $-0.3741 \times 10^{-3}$ \\
$h_{3}$ & $-0.30 \times 10^{-3}$ & $-0.3713 \times 10^{-3}$ \\
$h_{4}$ & $-0.20 \times 10^{-3}$ & $-0.2685 \times 10^{-3}$ \\
$h_{5}$ & $-0.10 \times 10^{-3}$ & $-0.6866 \times 10^{-4}$ \\
$h_{6}$ & 0.0 & $0.3185 \times 10^{-4}$ \\
$h_{7}$ & $0.10 \times 10^{-3}$ & $0.1319 \times 10^{-3}$ \\
$h_{8}$ & $0.20 \times 10^{-3}$ & $0.2031 \times 10^{-3}$ \\
$h_{9}$ & $0.30 \times 10^{-3}$ & $0.2743 \times 10^{-3}$ \\
$h_{10}$ & $0.40 \times 10^{-3}$ & $0.3743 \times 10^{-3}$ \\
$h_{11}$ & $0.50 \times 10^{-3}$ & $0.3743 \times 10^{-3}$ \\
$h_{12}$ & $0.60 \times 10^{-3}$ & $0.4740 \times 10^{-3}$
\end{tabular}


Table 7. Cylindrical shell with concentrated load $P$ at $Z=L / 2$ and $\theta=0$. Sensitivity of maximum displacement $\partial w / \partial \alpha_{i}$ and stress failure criterion (SFC) $\partial \psi_{j} / \partial \alpha_{i}$ (eqn (61))

\begin{tabular}{|c|c|c|c|}
\hline & & Displacement & Strain energy \\
\hline$\alpha_{0}$ & $\begin{array}{l}\text { Analytical } \\
\text { SA } \\
\text { GFD }\end{array}$ & $\begin{array}{l}\quad 0.0 \\
-0.200889 \times 10^{-8} \\
-0.200684 \times 10^{-8}\end{array}$ & $\begin{array}{l}0.235765 \times 10^{-2} \\
0.235767 \times 10^{-2} \\
0.235961 \times 10^{-2}\end{array}$ \\
\hline$\alpha_{1}$ & $\begin{array}{l}\text { Analytical } \\
\text { SA } \\
\text { GFD }\end{array}$ & $\begin{array}{l}0.0 \\
-0.363465 \times 10^{-10} \\
-0.324760 \times 10^{-10}\end{array}$ & $\begin{array}{l}0.202077 \times 10^{-2} \\
0.202078 \times 10^{-2} \\
0.202237 \times 10^{-2}\end{array}$ \\
\hline$\alpha_{2}$ & $\begin{array}{l}\text { Analytical } \\
\text { SA } \\
\text { GFD }\end{array}$ & $\begin{array}{l}\quad 0.0 \\
-0.155495 \times 10^{-8} \\
-0.155442 \times 10^{-8}\end{array}$ & $\begin{array}{l}0.223009 \times 10^{-2} \\
0.223010 \times 10^{-2} \\
0.223193 \times 10^{-2}\end{array}$ \\
\hline$\alpha_{3}$ & $\begin{array}{l}\text { Analytical } \\
\text { SA } \\
\text { GFD }\end{array}$ & $\begin{array}{l}0.0 \\
-0.989202 \times 10^{-9} \\
-0.984649 \times 19^{-9}\end{array}$ & $\begin{array}{l}0.190968 \times 10^{-2} \\
0.190969 \times 10^{-2} \\
0.191119 \times 10^{-2}\end{array}$ \\
\hline$\alpha_{4}$ & $\begin{array}{l}\text { Analytical } \\
\text { SA } \\
\text { GFD }\end{array}$ & $\begin{array}{l}0.0 \\
-0.121165 \times 10^{-8} \\
-0.120810 \times 10^{-8}\end{array}$ & $\begin{array}{l}0.211137 \times 10^{-2} \\
0.211138 \times 10^{-2} \\
0.211312 \times 10^{-2}\end{array}$ \\
\hline$\alpha_{5}$ & $\begin{array}{l}\text { Analytical } \\
\text { SA } \\
\text { GFD }\end{array}$ & $\begin{array}{l}\quad 0.0 \\
-0.132478 \times 10^{-8} \\
-0.132052 \times 10^{-8}\end{array}$ & $\begin{array}{l}0.180752 \times 10^{-2} \\
0.180753 \times 10^{-2} \\
0.180895 \times 10^{-2}\end{array}$ \\
\hline$\alpha_{6}$ & $\begin{array}{l}\text { Analytical } \\
\text { SA } \\
\text { GFD }\end{array}$ & $\begin{array}{l}0.0 \\
-0.126152 \times 10^{-8} \\
-0.125711 \times 10^{-8}\end{array}$ & $\begin{array}{l}0.175979 \times 10^{-2} \\
0.175980 \times 10^{-2} \\
0.176118 \times 10^{-2}\end{array}$ \\
\hline$\alpha_{7}$ & $\begin{array}{l}\text { Analytical } \\
\text { SA } \\
\text { GFD }\end{array}$ & $\begin{array}{l}0.0 \\
-0.925597 \times 109 \\
-0.923728 \times 10^{-9}\end{array}$ & $\begin{array}{l}0.194988 \times 10^{-2} \\
0.194989 \times 10^{-2} \\
0.195150 \times 10^{-2}\end{array}$ \\
\hline$\alpha_{8}$ & $\begin{array}{l}\text { Analytical } \\
\text { SA } \\
\text { GFD }\end{array}$ & $\begin{array}{l}\quad 0.0 \\
-0.659862 \times 10^{-9} \\
-0.655347 \times 10^{-9}\end{array}$ & $\begin{array}{l}0.167103 \times 10^{-2} \\
0.167104 \times 10^{-2} \\
0.167236 \times 10^{-2}\end{array}$ \\
\hline$\alpha_{9}$ & $\begin{array}{l}\text { Analytical } \\
\text { SA } \\
\text { GFD }\end{array}$ & $\begin{array}{l}0.0 \\
-0.883283 \times 109 \\
-0.880816 \times 10^{-9}\end{array}$ & $\begin{array}{l}0.185328 \times 10^{-2} \\
0.185329 \times 10^{-2} \\
0.185482 \times 10^{-2}\end{array}$ \\
\hline$\alpha_{10}$ & $\begin{array}{l}\text { Analytical } \\
\text { SA } \\
\text { GFD }\end{array}$ & $\begin{array}{l}\quad 0.0 \\
-0.559220 \times 10^{-9} \\
-0.563215 \times 10^{-9}\end{array}$ & $\begin{array}{l}0.159121 \times 10^{-2} \\
0.159122 \times 10^{-2} \\
0.159247 \times 10^{-2}\end{array}$ \\
\hline$\alpha_{11}$ & $\begin{array}{l}\text { Analytical } \\
\text { SA } \\
\text { GFD }\end{array}$ & $\begin{array}{l}0.0 \\
-0.957605 \times 10^{-9} \\
-0.956086 \times 10^{-9}\end{array}$ & $\begin{array}{l}0.176553 \times 10^{-2} \\
0.176554 \times 10^{-2} \\
0.176699 \times 10^{-2}\end{array}$ \\
\hline
\end{tabular}

SA; GFD: $\delta \alpha_{i}=0.001^{\circ}$.

The coupling effects between the symmetric and antisymmetric degrees of freedom induce alterations in the response of the axisymmetric structures as shown for the values of the natural frequencies and mode shape in the circumferential direction of the conical shell example.

The results show that the static and dynamic analyses and the corresponding sensitivities of statical or dynamic functions (free vibrations) and/or constraints are efficiently obtained using the present model.

From the observation of results one can conclude that analytical, semi-analytical and global forward finite difference sensitivities are obtained with good accuracy when the design variables are the angles of orientation of the plies and the vectorial distances from middle surface to upper surface of each ply. The analytical discrete model is more efficient with regard to CPU time.

The semi-analytical and global finite difference sensitivities are efficiently obtained with the perturbations of $\alpha_{i}=0.001^{\circ}$ and $\delta h_{i}=10^{-5} h$. No numerical instabilities have been recorded with the finite difference for the two types of design variables considered in the present work.

The proposed discrete model, in association with the algorithms of DavidsonFletcher-Powel variable metric and modified feasible directions method, makes an adequate tool to obtain the optimal design of multilayered axisymmetric shell structures. 
Table 8. Cylindrical shell with concentrated load $P$ at $Z=L / 2$ and $\theta=0$. Sensitivity of maximum displacement $\partial w / \partial h_{i}$ and stress failure criterion (SFC) $\partial \psi_{j} / \partial h_{i}$ (eqn (61))

\begin{tabular}{|c|c|c|c|}
\hline & & Displacement & Strain energy \\
\hline$h_{0}$ & $\begin{array}{l}\text { Analytical } \\
\text { SA } \\
\text { GFD }\end{array}$ & $\begin{array}{l}0.49991 \times 10^{-1} \\
0.49993 \times 10^{-1} \\
0.49994 \times 10^{-1}\end{array}$ & $\begin{array}{l}0.89866 \times 10^{-1} \\
0.89875 \times 10^{-2} \\
0.89889 \times 10^{-2}\end{array}$ \\
\hline$h_{1}$ & $\begin{array}{l}\text { Analytical } \\
\text { SA } \\
\text { GFD }\end{array}$ & $\begin{array}{l}0.44879 \times 10^{-1} \\
0.44880 \times 10^{-1} \\
0.44886 \times 10^{-1}\end{array}$ & $\begin{array}{l}0.10178 \times 10^{-2} \\
0.10182 \times 10^{-2} \\
0.10189 \times 10^{-2}\end{array}$ \\
\hline$h_{2}$ & $\begin{array}{l}\text { Analytical } \\
\text { SA } \\
\text { GFD }\end{array}$ & $\begin{array}{l}-0.27112 \times 10^{-1} \\
-0.27108 \times 10^{-1} \\
-0.27094 \times 10^{-1}\end{array}$ & $\begin{array}{l}-0.14817 \times 10^{-2} \\
-0.14812 \times 10^{-2} \\
-0.14804 \times 10^{-2}\end{array}$ \\
\hline$h_{3}$ & $\begin{array}{l}\text { Analytical } \\
\text { SA } \\
\text { GFD }\end{array}$ & $\begin{array}{l}0.13159 \times 10^{-1} \\
0.13157 \times 10^{-1} \\
0.13156 \times 10^{-1}\end{array}$ & $\begin{array}{l}-0.41698 \times 10^{-3} \\
-0.41686 \times 10^{-3} \\
-0.41674 \times 10^{-3}\end{array}$ \\
\hline$h_{4}$ & $\begin{array}{l}\text { Analytical } \\
\text { SA } \\
\text { GFD }\end{array}$ & $\begin{array}{l}-0.30181 \times 10^{-2} \\
-0.30168 \times 10^{-2} \\
-0.30114 \times 10^{-2}\end{array}$ & $\begin{array}{l}-0.71785 \times 10^{-3} \\
-0.71771 \times 10^{-3} \\
-0.71765 \times 10^{-3}\end{array}$ \\
\hline$h_{5}$ & $\begin{array}{l}\text { Analytical } \\
\text { SA } \\
\text { GFD }\end{array}$ & $\begin{array}{l}-0.33098 \times 10^{-2} \\
-0.30100 \times 10^{-2} \\
-0.33115 \times 10^{-2}\end{array}$ & $\begin{array}{l}-0.46075 \times 10^{-3} \\
-0.46060 \times 10^{-3} \\
-0.46056 \times 10^{-3}\end{array}$ \\
\hline$h_{6}$ & $\begin{array}{l}\text { Analytical } \\
\text { SA } \\
\text { GFD }\end{array}$ & $\begin{array}{l}0.00 \\
0.00 \\
0.00\end{array}$ & $\begin{array}{l}-0.55362 \times 10^{-3} \\
-0.55361 \times 10^{-3} \\
-0.55360 \times 10^{-3}\end{array}$ \\
\hline$h_{7}$ & $\begin{array}{l}\text { Analytical } \\
\text { SA } \\
\text { GFD }\end{array}$ & $\begin{array}{l}0.45274 \times 10^{-2} \\
0.45270 \times 10^{-2} \\
0.45268 \times 10^{-2}\end{array}$ & $\begin{array}{l}-0.14514 \times 10^{-2} \\
-0.14516 \times 10^{-2} \\
-0.14517 \times 10^{-2}\end{array}$ \\
\hline$h_{8}$ & $\begin{array}{l}\text { Analytical } \\
\text { SA } \\
\text { GFD }\end{array}$ & $\begin{array}{l}0.58294 \times 10^{-3} \\
0.58250 \times 10^{-3} \\
0.58947 \times 10^{-3}\end{array}$ & $\begin{array}{l}0.85921 \times 10^{-3} \\
0.85932 \times 10^{-3} \\
0.85952 \times 10^{-3}\end{array}$ \\
\hline$h_{9}$ & $\begin{array}{l}\text { Analytical } \\
\text { SA } \\
\text { GFD }\end{array}$ & $\begin{array}{l}-0.95061 \times 10^{-2} \\
-0.95070 \times 10^{-2} \\
-0.95079 \times 10^{-2}\end{array}$ & $\begin{array}{l}-0.24705 \times 10^{-2} \\
-0.24705 \times 10^{-2} \\
-0.24704 \times 10^{-2}\end{array}$ \\
\hline$h_{10}$ & $\begin{array}{l}\text { Analytical } \\
\text { SA } \\
\text { GFD }\end{array}$ & $\begin{array}{l}0.22242 \times 10^{-1} \\
0.22250 \times 10^{-1} \\
0.22260 \times 10^{-1}\end{array}$ & $\begin{array}{l}0.20186 \times 10^{-2} \\
0.20180 \times 10^{-2} \\
0.20193 \times 10^{-2}\end{array}$ \\
\hline$h_{11}$ & $\begin{array}{l}\text { Analytical } \\
\text { SA } \\
\text { GFD }\end{array}$ & $\begin{array}{l}-0.38791 \times 10^{-1} \\
-0.38786 \times 10^{-1} \\
-0.38783 \times 10^{-1}\end{array}$ & $\begin{array}{l}-0.34716 \times 10^{-2} \\
-0.34717 \times 10^{-2} \\
-0.34719 \times 10^{-2}\end{array}$ \\
\hline$h_{12}$ & $\begin{array}{l}\text { Analytical } \\
\text { SA } \\
\text { GFD }\end{array}$ & $\begin{array}{l}-0.52327 \times 10^{-1} \\
-0.52325 \times 10^{-1} \\
-0.52322 \times 10^{-1}\end{array}$ & $\begin{array}{l}-0.13021 \times 10^{-3} \\
-0.13021 \times 10^{-3} \\
-0.13020 \times 10^{-3}\end{array}$ \\
\hline
\end{tabular}

SA; GFD: $\delta h_{i}=10^{-5} h$.

Acknowledgements-The authors wish to thank the financial support given by JNICT-Junta Nacional de Investigação Científica e Tecnológica (Prj. STRD/A/TPR/592/92) and FLAD-Fundação Luso Americana para o Desenvolvimento.

\section{REFERENCES}

Barbosa, J. I., Mota Soares, C. M. and Mota Soares, C. A. (1991). Sensitivity analysis and shape optimal design of axisymmetric shell structures. Computing Systems in Engineering 2(5/6), 525-533.

Barthelemy, B., Chon, C. T. and Haftka, R. T. (1988). Accuracy problems associated with semi-analytical derivatives of static response. J. Finite Elements in Analysis and Design 4, 249-265.

Bellendir, K. and Eschenauer, H. A. (1993). Optimal design of composite lightweight rollers. In Advances in Design Automation, Vol. 65-1 (Edited by B. J. Gilmore, D. A Hoeltzel, S. Azarm and E. A. Eschenauer), pp. 139-147. ASME, New York.

Bernadou, M., Palma, F. J. and Rousselet, B. (1991). Shape optimization of an elastic thin shell under various criteria. Structural Optimization 3(1), 7-21.

Blackut, J. (1993). On optimal end closures made from woven CFRP. In Optimal Design with Advanced Materials (Edited by P. Pedersen), pp. 367-382. Elsevier, Amsterdam.

Chenais, D. (1987). Shape optimization in shell theory: Design sensitivity of the continuous problem. Engineering Optimization 11, 289-303.

Correia, V. M. F. (1990). Método dos Elementos Finitos na Análise de Sensibilidades de Estruturas Construídas de Materiais Compósitos. MSc Thesis, Dep. Mechanical Eng., IST, Technical University of Lisbon, Portugal (in Portuguese). 
Haftka, R. T. and Kamat, M. P. (1987). Finite elements in structural design. In Computer Aided Optimal Design: Structural and Mechanical Systems (Edited by C. A. Mota Soares), pp. 241-270. Springer-Verlag, Berlin.

Haftka, R. and Gurdal, Z. (1993). Elements of Structural Optimization. 3rd edn. Kluwer Academic Press, Dordrecht.

Kraus, H. (1967). Thin Elastic Shells. John Wiley, New York.

Marcelin, J. L. and Trompetta, Ph. (1988). Optimal shape design of thin axisymmetric shells. Engineering Optimization 13, 108-117.

Mehrez, S. and Rousselet, B. (1989). Analysis and optimization of a shell of revolution. In Computer Aided Optimum Design of Structures: Applications (Edited by C. A. Brebbia and S. Hernandez), pp. 123-133. Computational Mechanics Publications, Springer-Verlag, Berlin.

Mota Soares, C. M., Mota Soares, C. A. and Barbosa, J. I. (1994). Sensitivity analysis and optimal design of thin shells of revolution. $A I A A J .32(5), 1034-1042$

Muc, A. (1992). On the buckling of composite shells of revolution under external pressure. Compos. Struct. 21(2), 106-119.

Plaut, R. H., Johnson, L. W. and Parbery, R. (1984). Optimal form of shallow shells with circular boundary. Transactions of the ASME 51, 526-538.

Sheinman, I. and Weissman, S. (1987). Coupling between symmetric and antisymmetric modes in shells of revolution. J. Comp. Mater. 21, 988-1007.

Tsai, S. W. and Hahn, H. T. (1980). Introduction to Composite Materials. Technomic.

Tooth, A. S., Banks, W. M. and Rahman, D. H. (1988). The specially orthotropic GRP multi-layered cylindrical shell-A theoretical approach for the general loading case. Compos. Struct. 9, 53-68.

Vanderplaats, G. N. (1984). Numerical Optimization Techniques for Engineering Design. McGraw-Hill, New York.

Vanderplaats, G. N. (1987). ADS-A Fortram Program for Automated Design Synthesis. Version 2.01. Engineering Design Optimization, Santa Barbara, CA, U.S.A.

Vinson, J. R. and Sienakowski, R. L. (1986). The Behavior of Structures Composed of Composite Materials. Martinus Nijhoff Publishers, Dordrecht.

Zienkiewicz, O. C. (1977). The Finite Element Method in Engineering Science, 3rd edn. McGraw-Hill, London.

Zienkiewicz, O. C. and Campbell, J. S. (1973). Shape optimization and sequential linear programming. In Optimum Structural Design (Edited by R. H. Gallagher and O. C. Zienkiewicz). Wiley, London.

Zimmerman, R. H. (1993). Multiobjective optimization of fiber composite shells for maximum buckling load and imperfection tolerance. In Advances in Design Automation, Vol. 65-1 (Edited by G. J. Gilmore, D. A. Hoeltzel, S. Azarm and E. A. Eschenauer), pp. 631-636. ASME, New York. 